\title{
Cooperación y conflicto en la Cuenca del Plata*
}

INTRODUCCION

Una parte del esfuerzo de los países latinoamericanos por superar el problema del desarrollo ha estado centrado en el establecimiento de mecanismos multilaterales de interacción económica. En las dos últimas décadas, a partir del Tratado de Montevideo, tal empresa ha tenido expresión en una variedad de modalidades, tanto respecto a su contenido $y$ alcance, como a su estructura. Todas ellas han sido erigidas bajo el rótulo de la "integración" y todas han corporizado distintos grados de "cooperación". En algunas de ellas, además, está presente un factor conflictual inter-estadual, derivado tanto de razones históricas como de incompatibilidad de intereses - parciales o globales- nacionales.

Este artículo pretende sistematizar el sistema multilateral subregional de la Guenca del Plata, cuyo origen institucional reside en la firma del Tratado de Brasilia, en abril de 1969. En él se manifiesta por una parte la ambivalencia entre integración y cooperación -común a otros modelos multilaterales en la región- y, por la otra, la dualidad de conflicto y cooperación.

En la primera parte describimos el marco en que tuvo lugar el intento integracionista y la práctica cooperativa en América Latina, para situar el modelo de la Cuenca del Plata. En la segunda parte, junto con unas notas conceptuales, señalamos las tendencias conflictuales y cooperativas, ordenándolas en un modelo que se formula. Como se advierte en la nota final, el estudio analíticoempírico del modelo formulado corresponde a una fase posterior de la investigación de la cual este trabajo forma parte.

*Trabajo de la investigación Cooperación y Confliclo en la Cuenca del Plata, que dirige el profesor Dieter Nohlen en. el Instituto de Ciencia Política de la Universidad de Heidelberg. 
I. INTEGRACION Y COOPERAGION EN AMERICA LATINA. DE LA ALALC A LA GUENGA DEL PLATA

\section{Integración económica en América Latina. Idea y realidad}

La creación de la ALADI en agosto de 1980 constituyó un reconocimiento expreso de que la crisis de la ALALC no podía resolverse en los marcos del Tratado de Montevideo. Ni para quienes esperaban que el modelo erigido en 1960 representara un paso inicial hacia estadios superiores de integración, ni para los que veían en él un mecanismo destinado a liberar el comercio intralatinoamericano en grandes proporciones, ALALC resultó, en 20 años de vida, un sistema satisfactorio.

Para unos y para otros - para los desarrollistas y los comercialistas $^{1}$ - el paso dado en 1980 era un dato esperado desde hace mucho. En 1967, con el acuerdo de compatibilización entre AlaLc y acuerdos subregionales, los países -en gran medida los gobiernos- interesados en avanzar hacia la formación de un mercado común, volcaron sus esfuerzos integracionistas en el Grupo Andino. Por otra parte, desde el acuerdo explicitado en el Protocolo de Caracas en 1969 -que aplazó la formación de una zona de libre comercio de 1973 a 1980 - se acrecentaba la evidencia de que el modelo de liberalización del comercio cle la ALALC adolecía de defectos fundamentales.

A pesar de que han abundado los trabajos destinados a explicar los problemas del funcionamiento de la $\mathrm{ALALC}^{2}$, son pocos aquellos que han incursionado en el análisis de algunos factores de fondo, quizá porque ellos escapan a los límites que en una especie de autosocialización se han impuesto los estudiosos latinoamericanos. Uno de ellos es poner en tela de juicio la integración misma como vía eficiente hacia el desarrollo, por lo menos en los términos como ha sido planteada en América Latina.

La idea de integración como solución al embotellamiento del desarrollo en la región fue formulada por la CEPAI según los funclamentos del modelo gradual, como el iniciado en Europa Occi-

"Sobre las corrientes "comercialistas" y "desarrollistas", ver:

a) Magariños, Gustavo: Perspectivas históricas y actuales de la NLALc, en: Integración Latinoamericana, No 2, 1976, pp. 30-41.

b) Tami, Felipc: Reflexiones sobre las experiencias de integración económica en América Latina, en: Integración Latinoamericana, No 28, 1978, pp. 4-15.

${ }^{2} U_{n}$ buen ejemplo de la temática adoptada por los trabajos de evaluación de la Alalc, se encuentra en los debates del seminario sobre la reestructuración de ALALC celebrado en el INTAL en septiembre de 1979. El texto de las intervenciones y de los acuerdos está publicado en: INTAC/BID: El proceso de Integración en América Latina en 1979, Buenos Aires, 1980, p. $75 \mathrm{y}$ siguientes. 
dental en $1957^{3}$. La realidad del Tratado de Montevideo no aceptó tales bases, limitándose a establecer un modelo de liberalización del comercio. Desde la partida, entonces, el modelo de "integración" latinoamericano no correspondía al fenómeno definido como tal en la literatura científica a partir de los años 50 . Teniendo presente este hecho, sin embargo, la terminología permaneció in. variable, intentándose mediante la costumbre legitimar el uso de un concepto para un fenómeno que no tenía lugar.

Esta contradicción concepto-objeto trajo consigo una serie de distorsiones entre el ámbito de la abstracción y el de la retórica por una parte $\mathrm{y}$ las verdaderas características del proceso real por la otra4. Mientras se hablaba de "problemas" en el proceso de integración o de "disposición" para continuar en el proceso de integración, lo empírico señalaba que una mínima parte de lo logrado correspondía a los objetivos de 1960 , teniendo en cuenta además Io señalado en lo que respecta a la distancia existente entre el Tratado de Montevideo y un modelo real de integración. Siendo el aumento del comercio intrazonal el único gran logro de la ALALC (junto con el impulso a la interdependencia parcial a la que nos referimos más adelante), aunque, no asi su liberalización en un grado relevante, la contradicción arriba señalada subsiste en el texto del Tratado de Montevideo 1980, que crea la ALADI. En el preámbulo del Tratado, los firmantes se manifiestan "decididos" a reno-

${ }^{3}$ En una intervención del estudioso Germánico Salgado hecha en el seminario en la nota 2, se menciona un dato interesante respecto al contenido de las proposiciones de la CEPAL respecto a la integración: “... de la ALAIC no se puede pedir otra cosa que una zona preferencial. Estas fueron las ideas originales de la CEPAL y de los primeros paises que se agruparon en los primeros grupos de trabajo de la creación del Mercado Común Latinoamericano. $Y$ si pasamos a hablar de la zona de libre comercio, fue por influencia, en ese caso mal dada, del GATT y del Gobicmo de Estados Unidos", (INTAL/BID: Ob. cit.. p. 107) .

Lo cierto, sin embargo, es que el pensamiento oficial de la CEPAL se inclinó por el modelo de integración gradualista. Así se expresa textualmente en un trabajo publicado en 1965: "No queda, en consecuencia, otro camino que el de establecer un proceso gradual de integración que lleve a una unión económica de los palses latinoamericanos" (CEPAL: El pensamiento de la GEPAL, Santiago de Chile, 1969, p. 169. Citado del trabajo de CEPAL: Contribución a la política de integración económica de América Latina, E/GN 12/728, 3 de junio de 1965).

"Un ejemplo de las distorsiones señaladas, está dado por la concepción prevaleciente en amplios círculos latinoamericanos respecto a la supranacionalidad. la que en estricto sentido no sólo no se dio en el marco latinoamericano, sino que tampoco podía darse en un modelo cuyas metas no incluian la integra-
ción política o la unión económica. (Sobre el punto ver: Orrego Vicuña, Francisco: Los presupuestos jurídicos de un proceso de integración económica efectivo, en: Derecho de la Integración, No 24, 1977, pp. I1-19. 
var el proceso de integración..." pleno desarrollo en el marco de la ALALc.

Lo cierto es que la práctica multilateral latinoamericana de los últimos veinte años consiste en un aumento de la cooperación económica, la que ciertamente se ha enriquecido a causa de su diversificación en cuanto a las modalidades y a los rubros que ha abarcado. Sí tomamos cualquier concepto que se tenga de integración -incluso el implícito en el modelo de la ALALC- debemos reconocer que la tendencia en América Latina es, incluso, regresiva. Al iniciarse los últimos veinte años del sigIo, existe menos disposición política -que es la que al final es determinante para el logro de estos procesos- de los países de la región para integrarse en un modelo multilateral, con organismos verdaderamente supranacionales y con un proyecto global a largo plazo y realizable 6 .

\section{De la idea integracionista a la práctica de la cooperación. El caso de la Cuenca del Plata}

En la mayoría de las explicaciones que se han intentado para el fracaso de un sistema de integración global para América Latina, subyace una concepción de la heterogeneidad latinoamericana. Sea ésta la heterogeneidad estructural interna de cada país, la heterogeneidad entre distintos grados de desarrollo entre los países o la heterogeneidad entre los regímenes políticos o sistemas sociales, la idea central consiste en que es muy difícil de alcanzar un nivel avanzado de integración supranacional en una región donde persisten diferencias multifacéticas tan hondas. El hecho de que la insistencia por llevar a cabo un modelo integracionista haya tenido lugar entre los países andinos -cuyas diferencias pueden ser compensadas con un alto volumen de similitudes- puede tomarse como un apoyo a tal afirmación.

Por otra parte, sin embargo, el impulso integracionista mostró. las ventajas que podrían acarrear iniciativas intrarregionales de cooperación. Aunque la experiencia de la ALALG fracasó en gran parte debido a la presencia de nacionalismos muy marcados, el aumento de interacción entre los páses produjo una cierta moderación de aquellos bajo el signo del pragmatismo. Si bien, por una parte, quedó en claro que un sistema de liberalización comercial global beneficiaba a los países de mayor desarrollo y perjudicaba a

\footnotetext{
Ver texto del Tratado de Montevideo 1980, párrafo 49 del preámbulo. (Texto oficial de la Secretaría de la ALALC, 1980).

-Una exhaustiva revisión a la teorfa de la integración, con sus diversos "approaches" se encuentra en la tesis doctoral de Celson J. da Silva: RegionaIe Integration in einer Dependenzsituation. Der Fall Lateinamerikas, Inagural Dissertation de la Facultad de Filosofía de la Universidad de Heidelberg, Heidelberg, 1980, cap. vIr, virI y Ix. (Hay versión en portugués).
} 
los más atrasados, también se hizo evidente - para unos y otrosque, en determinados ámbitos y entre determinados países, podrían establecerse acuerdos con beneficios equitativos. La experiencia de la ALALG mostró, por una parte, la improbabilidad de una integración global en la región, pero, simultáneamente, la viabilidad y conveniencia de una interdependencia limitada y múltiple. Las tenclencias a la cooperación, en gran parte, acompañadas por un retor. no al bilateralismo, se dieron desde el inicio del sistema de la ALALC, pero proliferaron a partir de su crisis. Incluso, tanto los organismos como los dirigentes del proceso iniciado por el Tratado de Montevideo, empezaron a insistir en una diferenciación conceptual dentro de "integración", según la cual, ésta debía entenderse tanto en un sentido estricto (un proceso orientado a la formación de un mercado multinacional), como en un sentido amplio (que se superpone con el concepto de cooperación regionalt. A partir de 1976, el Instituto para la Integración Latinoamericana (INTAL), inició una investigación sobre las distintas modalidades de cooperación en el marco regional y varios artículos de estudiosos latinoamericanos han isido destinados al tema en los últimos años $s$.

Del mismo modo como el Pacto Andino surgió como una iniciativa de la tesis "desarrollista-integracionista", el Tratado de la Guenca del Plata, firmado en Brasilia el 23 de abril de 1969, constituyó en cierto modo, una concreción de la corriente "pragmáticacooperacionista". Los cinco países firmantes - Argentina, Bolivia, Brasil, Paraguay y Uruguay- forman, por una parte, una buenz muestra de la heterogeneidad latinoamericana ya señalada', $y$, por la otra, son partes de una unidad geográfica, cuyo aprovechamien. to económico sólo es viable mediante una serie de acuerdos entre ellos. Tomando los objetivos de los mecanismos de cooperación señalados por Tomassini10, el Tratado de la Cuenca clel Plata habría surgido de la necesidad de "maximizar la utilización de los recursos naturales de la región", tarea que trasciende a la capacidad de cada uno de los países con participación territorial en la Cuenca.

TDocumento de INTAL ATI42, del 15 de junio de 1972, p. 5 (citado en: Greño Velasco, José Enrique: Perfil de un nuevo sistema latinoamericano de relaciones regionales, en: Revista Argentina de Relaciones Internacionales, No 12, 1978, pp. 64-74).

${ }^{8}$ Como parte de esta investigación, ver Tomassini, Luciano: Elementos para el cstudio de los procesos de integración y otras formas de cooperación en América Latina, en: Integración Latinoamericana, No 12, 1977, pp. 22-42. Sobre las formas de cooperación, ver: Echegaray, Alfredo: Factores y modalidades de la cooperación económica en América Latina, en: Centro de Economía Humana: Desarrollo Latinoamericano. De la raíz al desafio, Montevideo, 1977, pp. 45-59.

10Tomassini, Luciano: Hacia nuevas formas de cooperación latinoamericana, en: Comercio Exterior, No 4, 1975, pp. 422-434. 
D. Nohlen y M. Fernández / Cooperación y conflicto en la Cuenca...

Esta inmensa región, con una superficie superior a los 3 millones de $\mathrm{Km} .{ }^{2}$, es considerada una de las zonas potencialmente más ricas en recursos y condiciones naturales del mundo.

TABLA 1: DIMENSIONES DE LA GUENCA DEL PLATA

Superficie

Total de la Cuenca

$3.163 .653 \mathrm{Km} .^{\mathrm{s}}$

\begin{tabular}{lcccc}
\hline & $\begin{array}{c}\text { Total del pais Superficie de cada } \\
\left(\text { Km. } .^{2}\right) \\
\text { pais en la Cuenca } \\
\left(\text { Km. } .^{2}\right)\end{array}$ & $\begin{array}{c}\text { \%el total del } \\
\text { pais en la } \\
\text { Cuenca }\end{array}$ & $\begin{array}{c}\% \text { de la } \\
\text { Cuenca } \\
\text { en cada } \\
\text { pais }\end{array}$ \\
\hline Argentina & 2.758 .829 & 1.033 .800 & 37,4 & 32,0 \\
Bolivia & 1.098 .581 & 204.000 & 13,5 & 6,0 \\
Brasil & 8.511 .965 & 1.414 .200 & 16,6 & 44,0 \\
Paraguay & 406.752 & 406.752 & 100,0 & 13,0 \\
Uruguay & 117.508 & 104.901 & 79,34 & 5,0 \\
\hline
\end{tabular}

LUeNTE: Kempff, Rolando: Proceso cle integración de la Cuenca del Plata, en: Revista Argentina de Relaciones Internacionales, No 9, septiembre-diciembre 1977 , pp. 69-85.

Las negociaciones tendientes al acuerdo entre los países de la Guenca se iniciaron en febrero de 1967, al celebrarse en Buenos Aires la primera Conferencia de Ministros de Relaciones Exterio-

9 Datos basicos de los países de la Guenca dec Plata

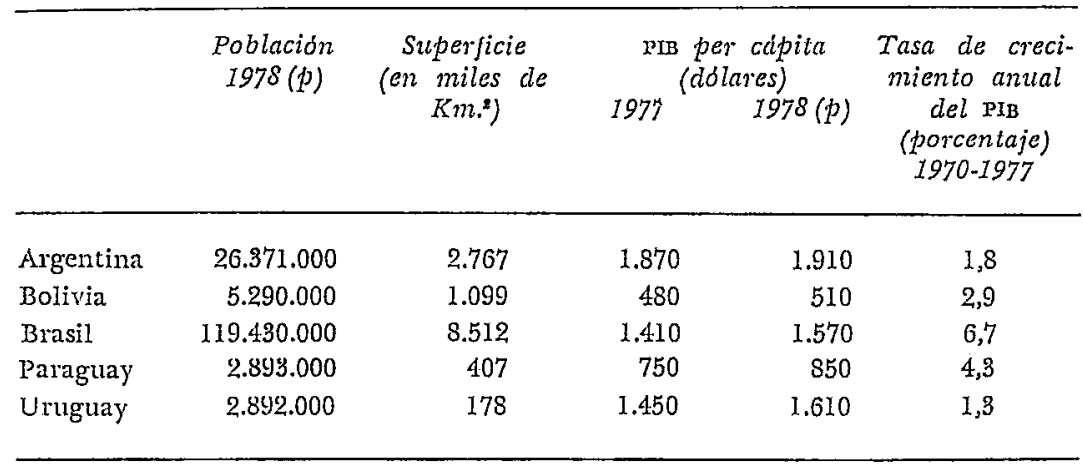

(p) Apreciación preliminar.

FunNTE: 1979, World Bank Atlas, p. 20, y (World Bank): Weltentwicklungsbericht 1978, pp. 88-89. 
res de los países de la Guenca. Gomo resultado de ella, se tomó un acuerdo en el sentido de "llevar a cabo un estudio conjunto e integral de la Guenca del Plata, con miras a la realización de un programa de obras multinacionales, bilaterales y nacionales, útiles al progxeso de la región"11. El concepto-base sobre el cual se llevó a cabo el acuerdo, fue el de "integración física", el que, incorporando el término "integración" más que nada para seguir una tradición de "uso" de los años 50 y 60 en el ámbito científico de América Latina, se refería básicamente a acuerdos internacionales entre países vecinos para promover obras de infraestructura de utilidad común ${ }^{12}$. Aunque en distintos grados, la potencialidad del uso global de los recursos de la zona, formaba parte del interés de todos los países: Por ejemplo, el uso energético especialmente para Brasil y Argentina, cuyos centros industriales forman parte de la Cuenca; la navegación y las comunicaciones, de primera importancia para Bolivia y Paraguay a causa de su mediterraneidad; o el interés de Argentina y Uruguay de evitar perjuicios por el uso de los ríos "aguas arriba" especialmente para su agricultura, debido a su posición de países ubicados en la desembocadura de la Cuenca.

\section{Estructura y funcionamiento del sistema de la Cuenca del Plata}

Los órganos establecidos en el Tratado de Brasilia carecen de rango supranacional13. A pesar de los intentos de los países menores por otorgar a los órganos del sistema autonomía respecto a los países miembros y obligar, por lo tanto, a éstos a delegar parte de su soberanía, prevaleció la tesis argentino-brasileña de dar al Tratado el carácter de "unión simple de Estados" y hacer radicar las facultades decisorias en la Conferencia de Cancilleres, la que no constituye un órgano del sistema, sino que se encuentra por sobre éstel4. El Tratado es aplicable al territorio de la Guenca y a "sus áreas de influencia directa y ponderable"15, lo que significa que los países partes de él, no se obligan con la totalidad de sus temitorios. El órgano permanente del sistema, provisto de las facultades ejecutivas es el Comité Intergubernamental Coordinador (GIC), con sede en

${ }^{71}$ Vex la Declaración Conjunta de los Cancilleres de los países de la Cuenca del Plata del 27. 2. 1967, punto No I.

IfVer Quadri, Mario: La Cuenca del Plata como replanteo de la filosofia integracionista latinoamericana, en: Revista de Política Internacional, mayo-junio de 1969, pp. 47-64.

${ }^{13}$ Sobre supranacionalidad ver nota 4 de este trabajo.

${ }^{1 *}$ Sobre la naturaleza jurídica del Tratado de Brasilia, ver White, Eduardo: El sistema de la Cuenca del Plata como método de cooperación internacional, en: Derecho de la Integración, 5, octubre de 1969, pp. 131-136.

${ }^{15}$ Greño Velasco, José Enrique: Pacto Amazónico y Tratado de la Cuenca del Plata. Analogías y Diferencias, en: Revista de Política Internacional, 165, septiembre-octubre de 1979, pp. 75-92. 
Buenos Aires. Aunque cuenta con una secretaría propia, el cic no es autónomo políticamente, ya que está integrado por representantes diplomáticos de los países miembros, quienes toman sus acuerdos por unanimidad. El cic está facultado para crear grupos de expertos y comisiones técnicas ad-hoc ${ }^{10}$, pero especialmente tiene $\mathrm{CO}$ mo tarea llevar a cabo las orientaciones y los objetivos fijados por la Conferencia de Cancilleres.

EI otro órgano principal del sistema es el Fondo Financiero para el Desarrollo de la Cuenca del Plata, creado en 1974, pero en funciones desde 1976. El Fondo, destinado a financiar en una primera etapa estudios de prefactibilidad, factibilidad $y$ diseño final de proyectos y de negociar financiamientos extemos para obras de infraestructura, está dotado de un capital inicial de 100 millones de dólares, aportados por los países miembros ${ }^{1 T}$.

Junto a la institucionaliclad del sistema del Tratado de Brasilia, existen otros mecanismos o estructuras - tanto permanentes como ad-hoc- cuyas funciones consisten en ofrecer marcos de negociaciones sobre problemas específicos o para promover iniciativas limitadas de cooperación entre miembros del sistema. Dichas estructuras constituyen, en parte, los ámbitos en los cuales tienen lugar los procesos más importantes del sistema de cooperación en la Cuenca del Plata, superando en relevancia a la institucionalidad del sistema a la que hemos aludido más arriba.

Al tipo de estructuras permanentes corresponde URUPABOL, agrupación de los tres países menores - Bolivia, Paraguay y Uruguayestablecida con el objeto de llevar a cabo programas de integración mutua y de mejorar sus respectivas capacidades de negociación frente a los países mayores del sistema. La iniciativa más importante de URUPABOL ha sido el convenio para crear una flota mercante común adaptada a las condiciones de navegación fluvial. URUPABOL tiene una Secretaría Permanente desde 1963, pero su institucionali. zación fue iniciada sólo el 21 de octubre de 1977 con la aprobación del acta que contiene el proyecto del Convenio Constitutivo de URUPABOL ${ }^{18}$. Bajo la denominación Comisión Mixta Permanente Uruguay-Paraguay-Bolivia, URUPABOL asistió como observador a la 8 a Reunión de Gancilleres de la Cuenca del Plata (Brasilia, 1976). A la 9a Reunión (1977, Asunción) asistió como Grupo URUPABOL.

10Ver Kempff, Rolando: Proceso de Integración de la Guenca del Plata, en Revista Argentina de Relaciones Internacionales, $N^{\circ} 9$, septiembre-cliciembre de 1977, pp. 69-85.

IT/er Kempff, Rolando: Fondo Financiero de Ia Cuenca del Plata, en: Revista Argentina de Relaciones Internacionales, No 11 , mayo-agosto de 1978, pp. 31-41.

${ }^{18} V_{e x}$ Greño Velasco, José Emrique: Relaciones horizontales en la Cuenca del Plata, en: Revista de Política Internacional, 147, septiembre-ocutbre de 1970, pp. 147-167. 
Cuadro Ne 1

ORGANIGRAMA DEL TRATADO DE LA CUENCA DEL PLATA

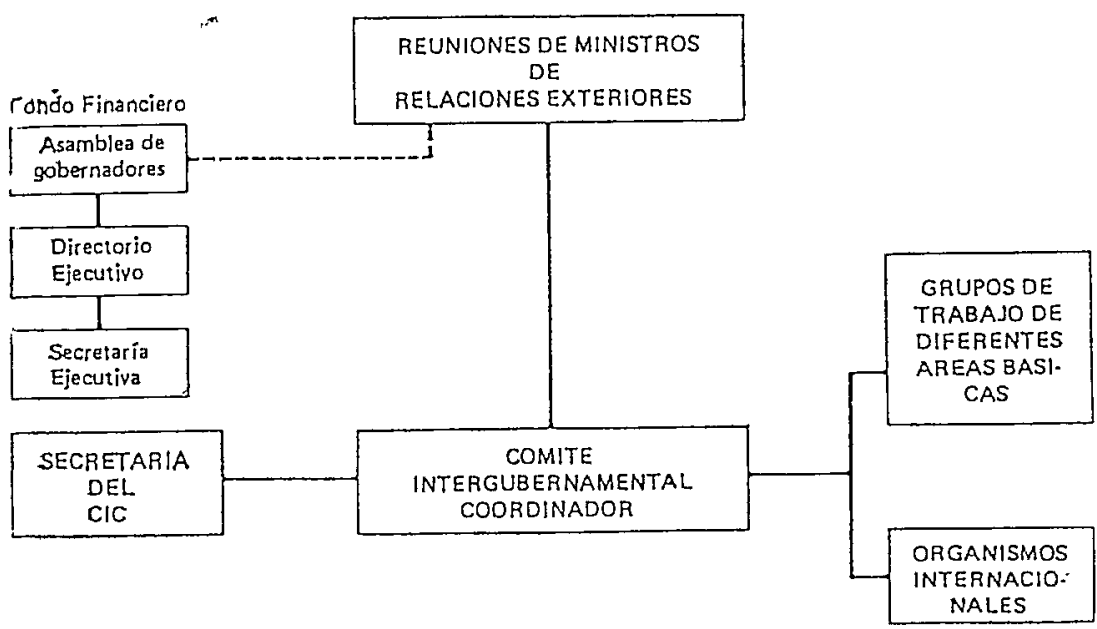

Fuente: Kempff, Rolando: Proceso de integración de la Cuenca del Plata, en Revista Argentina de Relaciones Internacionales, Año 3, No 9, Septiembre-Diciembre de 1977, p. 71.

Los mecanismos de mayor relevancia a través de los cuales ha funcionado el sistema de la Cuenca, ha consistido, sin embargo, en estructuras ad-hoc, establecidas para negociar "paquetes" de problemas bi o trilateralmente. Es el caso de las conversaciones tripartitas (o trilaterales), las que, con algún grado de institucionalidad y continuidad, tuvieron lugar entre Argentina, Brasil $y$ Paraguay durante dos años (1977-1979) con la finalidad de negociar los problemas derivados del aprovechamiento energético del rio Paraná.

Dentro del marco de estas conversaciones tuvo cabida una serie de problemas de diferente magnitud e índole, ligados al uso de las aguas, Como anotó un estudioso, Quagliotti de Bellis " (La Tripar- 
tita) ... ha trabajado en un esquema de suma y resta de problemas. De un concepto genérico de aprovechamiento múltiple y compartido de los rfos internacionales, al particular de las cotas de Itaipú y Corpus. Del costo y venta de la energía, al aumento de turbinas. De la navegabilidad del Paraná, a la construcción de puertos oceánicos en el litoral brasileño. De las consideraciones técnicas, al juego de poder diplomático-político"19.

Mirado descle un punto de vista integral, las conversaciones Tripartitas pusieron de manifiesto la complejidad que han alcanzado las relaciones entre Estados limítrofes latinoamericanos, cuando obligadamente se entrecruzan programas de desarrollo de vastas dimensiones. Se produce una mezcla de problemas técnicos, de incompatibilidad de intereses económicos, de tendencias históricas "perturbadoras" a la cooperación, del peso de escuelas geoestratégicas o geopolíticas, etc., junto a la urgencia de encontrar soluciones que impliquen la puesta en marcha de los respectivos proyectos ${ }^{20}$.

En el desarrollo de las conversaciones Tripartitas fue posible de observar toda esa gama de problemas y sus interrelaciones. La cuestión meramente técnica -reducida esquemáticamente a la ar-

\footnotetext{
${ }^{18}$ Sobre las negociaciones de las Tripartitas -aun cuando no alcanza a tratar el acuerdo de octubre de 1979- ver Quagliotti de Belis ${ }_{n}$ Bernardo: ItaipúCorpus: ¿Asunto técnico o político?, en: Geopolítica (Montevideo), No 7, abril de 1979, pp. 43-52.

${ }^{20}$ Especialmente descle el lado argentino se ha hecho más clara tal mezcia por las distintas posiciones existentes entre los estudiosos del problema, Las visiones tanto de la escuela nacionalista del almirante Rojas, como de la escuela geopolítica del general Guglialmelli han basado su rechazo a la política argentina en el problema Itaipú-Corpus y al acuerdo de las Tripartitas, tanto a partir de consideraciones geopolíticas como técnicas. Tal posición consiste en considerar a Itaipú como generadora de perjuicios para la navegación y para el aprovechamiento energético del Paraná argentino, lo que la construcción de Corpus -en las condiciones del arreglo de 1979- no será suficiente para evitar. Además, las condiciones de Corpus permitirá una rentabilidad mínima de la represa, la cual en ese caso no debicra haberse construido. La construcción de Itaipú, según esta versión, tiene una finalidad geopolítica básica para el Brasil, "siendo parte de un plan estratégico global para sellar un liderazgo continental".
}

(Sobre esta posición, ver los análisis y documentos publicados en Estrategia, Nos 61/62, noviembre-diciembre 1979 / enero-febrero 1980).

Paralela a esta visión se desarrolió una línea basada en criterios más pragmáticos y políticos. Según ella, tanto la construcción de Itaipú como la relación asimétrica Brasil-Argentina respecto al aprovechamiento energético en el Paraná, constituían hechos $y$, por lo tanto, sobre la base de tal realidad, había que formulax la política más óptima posiblc. Esta politica debía orientarse en buscar las bases del mayor equilibrio posible con Brasil-de ahí los "impasses" en las conversaciones txipartitas- para una relación de cooperación a largo plazo.

Esta segunda visión -que en definitiva fue la oficial argentina- se basa en una apreciación distinta (respecto a la línea nacionalista-geopolítica) del poder brasileño. Sus representantes parten del supuesto de que Brasil tiene de- 
monización entre la cota de Corpus y la potencia o el número de turbinas de Itaipú- sirvió de escenario para un complejo juego diplomático político en el cual se incubaba el tipo de relaciones que tendrían en el futuro los países implicados -especialmente Argentina y Brasil-, básicamente en el marco de la cooperación.

Como resultado político de las Tripartitas es posible comprobar dós hechos. Por una parte, apareció como evidencia que, a pesar de la desigualdad mutua en una serie de aspectos, se da un equilibrio en la relación. Argentina-Brasil. Este equilibrio implica que toda iniciativa de desarrollo, situada físicamente en la zona de la Cuenca del Plata, llevada a cabo por uno de los dos países, debe contar por lo menos con la opinión del otro. Esta obligatoriedad hacia la cooperación tuvo su manifestación concreta en una serie de convenios firmados por ambos países en mayo y agosto de 1980 , de los que nos ocuparemos más adelante.

El segundo elemento fue la mantención de Paraguay como paispéndulo entre los dos grandes paúses de la región. A pesar de que muchas opiniones -e interpretaciones es de algunos indicadores- señalaban que Paraguay estaba jugando una política inclinada claramente hacia Brasil, es posible deducir del desarrollo de las Tripartitas, que la política paraguaya contribuyó en parte decisiva para el acuerdo final, justamente a través de indicios destinados a demostrar que no actuaba en alianza con Brasil. Respecto a este punto, un alto negociador argentino señaló que la decisión paraguaya de rechazar el cambio de ciclaje del Paraguay, propuesto por Brasil, constituyó un punto clave de toda la negociación, pues indicó que la relación entre los socios de Itaipú tenía límites por la parte paraguaya.

\section{CONFLICTO Y GOOPERAGION EN LA GUENCA DEL PLATA. GONGEPTOS Y PROCESOS}

\section{Conflicto y Cooperación en el nivel teórico}

La acepción "conflicto" ha sido muy tratada, especialmente en el campo de la sociología y de las relaciones internacionales. Ello no significa que tanto esfuerzo haya logrado una cierta uniformidad conceptual. Como afirma Clinton F. Fink: "The resulting terminological and conceptual confusion may simply reflect the fact that

masiados problemas en su desarrollo para llevar a cabo con éxito cualquier política expansionista, especialmente a costa de Argentina. Por lo tanto, la conducta brasileña orientada a la cooperación no es meramente táctica, sino que responde a la realidad y a sus necesidades. (En esta línea es posible ubicar al Embajador de Argentina en Brasil, Oscar Camilión, a la Comisión Nacional de la Cuenca del Plata y entre los académicos, al jurista Félix Peña). 
scientific knowledge about social conflict has not yet moved to a level of analytical precision superior to that of common sense knowledge"21. En un primer nivel de diferenciación, sin embargo, consistente en considerar el conflicto como un fenómeno disociativo o asociativo, la mayoría de las opiniones se inclinan por la segunda opción, a través de exponentes tan connotados como Georg Simmel o Lewis Coser 22 .

La discusión se encuentra bastante más matizada en lo relativo al ámbito de situaciones que debiera abarcar el concepto. Habiendo una cierta unanimidad en considerar como característica básica del conflicto la existencia de una incompatibilidad entre las partes respecto a conseguir determinados objetivos u ocupar determinadas posıciones, las opiniones varían al precısar qué tipo de incompatibilidades o de antagonismos caben dentro de la categoría de conflictivas. Por una parte, se encuentran aquellos que sostienen la conveniencia de una definición amplia, como Ralf Dahrendorf ${ }^{23}$ (conflicto es "cualquiera relación de oposición de tipo objetivo o subjetivo") y otros abogan por un concepto restringido, como Werner Link" (conflicto es "un proceso, en cuyo desarrollo se produce una tensión crítica como resultado de tendencias incompatibles, las que están determinadas conscientemente por las partes y amenazan la organización o estructura de la unidad común a las partes"). La discusión entre estas posiciones, muy atractiva desde el punto de vista del contenido, tiene para nosotros un interés meramente operacional; se trata de optar por una definición que permita incorporax, de manera más sistemática, la variedad de situaciones que nos parecen contener elementos conflictivos.

Descle este utilitario punto de vista, pensando en la realidad de la interacción de actores en el sistema de la Cuenca del Plata, nuestra opción se inclina por aceptar la definición amplia de conflicto. Consideramos que ello no trae consigo -como teme Link- una "absolutización" del conflicto, conducente a "contradicciones" e "inconsistencias"25, si se tiene cuidado en diferenciar lo más cuidadosamente posible todas las situaciones susceptibles de ser abarcadas por el concepto. Basándose en los recursos del lenguaje, digamos que es preferible buscar adjetivos que sustantivos.

En el marco de la discusión señalada, sin embargo, persiste un

mFink, Glinton: Some conceptual difficulties in the Theory of Social Conflict, en Journal of Conflict Resolution, No 12, 1968, pp. 412-461 (430).

2Simmel, Georg: Der Streit, Leipzing, 1908; Coser, Lewis: The Functions of Social Conflict, Glencoe, 1955.

23ahrendorf, Ralf: Sociedad y Libertad, Madrid, 1971, p. 184.

"2kink, Werner: Überlegungen zum Begriff Konflikt in den Internationalen Beziehungen. Versuch der Begrifferklärung, en Politische Vierteljahresschrift, 20, No 1, 1979, pp. 33-50.

suLink, Werner, ob. cit.s p. 35. 
problema conceptual importante para nuestro tema empírico: las relaciones entre "conflicto" y "competencia". Según la tesis de la delinición restringida, la línea divisoria entre ambos conceptos radica en las consecuencias que, para la unidad que forman las partes, trae el antagonismo o el nivel de incompatibilidades. Si éstos ponen en peligro la organización o estructura de tal unidad, estamos en presencia de un conflicto. Si no es así, se "retrocede a la situación de competencia". El problema de esta diferenciación radica en la complejidad de precisar en qué momento está en peligro "potencial" una determinada unidad. La acepción amplia de conflicto considera la relación entre conflicto y competencia, como género-especie: Para Dahrendorf, "competencia" es un "conflicto regulado". Especialmente en el campo internacional, donde lo normal es la interacción entre los actores en relación antagónica, es difícil la adecuación del término competencia, que deriva en gran parte de una acepción economicista ${ }^{20}$. Siguiendo a Haas, el conflicto "es una oposición conductual entre fuerzas", lo que implica no sólo una interacción simpre en situación de poner en peligro la unidad de las partes, sino que el que ella cumple una función de estabilidad y existencia de dicha unidad ${ }^{27}$.

A pesar de implicar una iclea de "convergencia", el concepto de cooperación tiene en común con el "conflicto" tanto el supuesto de la existencia de partes con un objetivo compartido por ellas, como el de la incompatibilidad. Esta, sin embargo, no consiste en un antagonismo entre las partes respecto al logro del objetivo, sino en una incompatibilidad entre la capacidad de cada parte separada y el logro del objetivo. De ahí, que la dirección de la conducta de las partes es diferente a la propia del conflicto. Mientras en una prevalece el acuerdo, en la otra el desacuerdo"28. El acuerdo característico de la cooperación, sin embargo, se distingue de otros tipos de conductas convergentes (del consenso, por ejemplo). La cooperación consiste en una relación limitada a acuerdos respecto a pro. cedimientos para el ajuste de determinados problemas o sobre formas cle conducta, la que hace posible la mantención de diferencias entre las partes, tolerando incluso la existencia de algunas funda-

2هE1 intento más riguroso de diferenciar "conflicto" de "competencia", se encuentra quizás en la obra de Kenneth Boulding, (quien es economista): Conflict and Defense. A General Theory, N. York, 1962.

TTHass, Michael: International Conflict, Indianapolis-N. York, 1974 p. 491. EI rol funcional del conflicto, en el sentido de ser necesario para promover el cambio sociall, constituye la base argumentativa más sólida del concepto en Dahrendorf.

${ }^{2 y}$ Goldman, Ralph: Conflict, Cooperation and Choise: An Exploration of Conceptual Relationships, en Washburne, Norman (Ed.): Decisions Values and Groups, Oxford, London, N. York, Paris, 1962. 
mentales ${ }^{29}$. Una concretización de esta concepción está dada en el hecho de que el gran esfuerzo conceptual sobre "cooperación" en el marco de las relaciones internacionales, se haya producido a raíz del incremento de las relaciones comerciales entre los bloques capitalistas y socialistas de Europa a principios de la década del $70^{30}$. En la teoría de la integración económica, el concepto de cooperación se usó muchas veces como sinónimo de integración, aunque los estudios conceptuales más rigurosos se preocuparon de calificar al segundo concepto como un grado avanzado del primero ${ }^{31}$.

La escuela interaccionista del conflicto sostiene que éste y la cooperación son partes simultáneas de un mismo proceso ${ }^{32}$. Tal afirmación, se vio sostenida con las particularidades que alcanzó el sistema internacional de las grandes potencias después de la Segunda Guerra Mundial, en el que la solución del conflicto tendió a ser alcanzado mediante la cooperación. Todas las principales escuelas ocupadas de la "solución de conflictos" otorgaron un rol clave a la cooperación; tanto las sicologistas ${ }^{33}$, las matemático-behayouristas ${ }^{34}$ $y$ las estructuralistas ${ }^{35}$ (Friedensforschung).

Tal interacción entre conflicto y cooperación, explicitada más como una dualidad que como dicotomía ${ }^{36}$, es válida también para niveles de menor intensidad en cuanto se refiere al tipo de situación conflictual, como aquellas en las que no es probable una situación de empleo de la fuerza o de la ruptura completa de contacto entre las partes. Dentro de este tipo de relaciones de conflicto, ubicamos a aquellos antagonismos centrados en rivalidades tradicionales, de raíces históricas (como el "conflicto irreal" de Coser) o en la obtención de niveles de poder en la estratificación internacional (regional) incompatibles de ser ocupados simultáneamente por dos o

${ }^{2}$ Sobre la definición de cooperación a partir de un paralelo con "consenso", ver Horowitz, Irving Louis: Consensus, Conflict and Cooperation: A Sociological Inventory, en Social Forces, $N^{\circ} 41$, December 1962 pp. I77-188.

sover Galtung, Johan: A Theory of Peaceful Cooperation, en Galtung Johan (Ed.): Cooperation in Europe, Oslo, 1970, pp. 9-20.

"Sobre el uso amplio ver, por ej. Wionczek, Miguel (Ed.): Economic Cooperation in Latin America, Africa and Asia. A Handbook of Documents, Cambridge, Mass., 1969. Sobre la diferenciación entre ambos conceptos en la teoría de la integración ver Balassa, Bela: The Theory of Economic Integration, London, 1961, p. 2.

aVer Coser, Lewis: Ob. cit., 1956, primer capítulo.

Deutsch, Morton: The effects of cooperation and competition upon groups process, en Cartwright, Darwin y Zander, Alvin (Eds.): Group Dynamics, Evaston-N. York, 1962, pp. 414-418.

aRapoport, Anatol: Prospects for experimental games, en: Journal of Conflict Resolution, xII, 4, 1968, pp. 461-470.

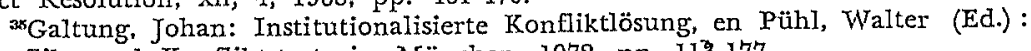
Konflikt und Konfliktstrategie, München, 1972, pp. I13-177.

${ }^{3 *}$ Claude Inis: Conflict, Cooperation and Consensus. The role of the U.N.: A Review, en: Journal of Conflict Resolution, $v, 1962$, pp. 166-168. 
más partes en pugna. En este caso, las tendencias cooperadoras resultantes no implican necesariamente una solución del conflicto, sino un cuadro de conducta alternativo y de existencia simultánea y compatible con aquél.

\section{Un modelo globalizador de Conflicto y Cooperación}

Siguiendo la línea de la definición global de "conflicto", en la que "cooperación" es posible de ser integrada, nos parece muy útil tomar el criterio de 'Czempiel37. Para él, "conflicto" sería "toda diferencia entre dos o más posiciones que se den en una o entre varias personas o grupos" $\mathrm{y}$, por lo tanto, el tipo de posiciones, el que ellas se ubiquen en el ámbito afectivo o cognocitivo, o qué conductas, opiniones, formas de comportamiento o acciones representen; son importantes para la clasificación, no para la definición. En el modelo o clasificación propuesto por Czempiel, basado en el criterio del grado de "violencia" dado en cada relación, ubica como situaciones extremas la "hostilidad" y la "integración", situándose "cooperación" en un grado intermedio, más cerca de integración.

El modelo de Czempiel (ver la nota 37), sin embargo, nos servirá de base, pues debemos modificarlos significativamente, especialmente en su contenido que hemos tenido que ampliarlo bastante. De la estructura del modelo hemos hecho una modificación importante, consistente en integrar dos categorías: "rivalidad" y "competencia", y eliminar una: "poder". Esta modificación resulta de las situaciones concretas que se dan en la Cuenca del Plata.

Nuestras variaciones al modelo de Czempiel derivan ciertamente del ámbito de aplicación. Czempiel propone un marco para ser entendidas las relaciones en el ámbito internacional global, de ahí que tiene relevancia categorías como "poder", "bloqueo", "amenaza militar", "boicot", etc. que se hallan implícitas en las relaciones entre los bloques de la política mundial. Por otra parte, el concepto "cooperación" tiene en la clasificación de Czempiel una acepción circunscrita a las relaciones entre el "Primer" y "Tercer" Mundo, debido a lo cual el "medio" por el cual tiene lugar es la "ayuda" . Nuestro concepto de "cooperación" está centrado en las relaciones dentro del Tercer Mundo y, por lo tanto, debe entenderse también como un tipo de relación "horizontal" que requiere ser caracterizada con más precisión.

Un último elemento a considerar en nuestra adaptación del modelo de Czempiel es la inclusión de dos niveles de situaciones, que llamamos "situación global" y "situación específica". La razón de

'Ver Czempiel, Ernest-Otto: Friede und Konflikt in der Gesellschaftlehre, en: Aus Politik und Zeitegeschichte, в 20/74, 18 mayo 1974, pp. 3-29. 
ello es para hacer urfa diferencia entre un concepto amplio de cooperación, como conducta tendiente a la convergencia, y en un sentido estricto, como ajuste conyuntural y concreto. Entendiendo al conflicto como la categoría globalizante, las situaciones entendidas dentro de cooperación en su sentido amplio, corresponden a la fase del conflicto donde las incompatibilidades 0 antagonismos tienden a lograr su mínimo nivel.

\section{Las raices históricas del conflicto en la Cuenca del Plata}

Con la excepción de Brasil con Bolivia, todos los países de la Cuenca del Plata han tenido conflictos bélicos entre sí. El antagonismo dominante, sin embargo está radicado entre Argentina y Brasil. Tal relación tiene tanto una proyección continental en toda Latinoamérica, como local, en el marco de la Cuenca del Plata. Por una parte, ambos países han sostenido una permanente rivalidad por ocupar la posición de poder dominante en el subcontinente, y por la otra, por influir entre los vecinos menores en la región platense. Ambos países juntos revresentan el $50 \%$ del territorio total latinoamericano, $y$ un $76 \%$ de la superficie platense; el $44 \%$ de la población latinoamericana, $y$ un $89,3 \%$ de los habitantes de la Cuenca. Su PBI alcanza al $44 \%$ de Latinoamérica ${ }^{88}$.

En el marco latinoamericano, ambos países se vieron favorecidos desde el momento de la Independencia para ocupar posiciones de poder regional. EI hecho de nue la Corte portuguesa de los Braganza se haya instalado desde 1807 en Brasil, y que a partir de 1822 se hava mantenido una monarquía independiente de Portugal, dio a Brasil una estabilidad polftica -difícil de encontrar en la región en la primera mitad del siglo 19-, que perduró hasta la formación de la "República Vieja" en 1889. Argentina, por su parte, si bien tardó medio siglo en lograr su integración nacional, mantuvo en Buenos Aires un centro de expansión de las guerras de la Independencia en el sur del Continente, sin haber sido nunca reconquistado por España, como aconteció transitoriamente con la casi totalidad de las otras colonias. La posición geográfica de ambos países, frente al Atlántico y la demanda de sus productos agxícolas y mineros, junto con obligarlos a constantes concesiones y negociaciones $-y$ muchas veces enfrentamientos- con las potencias comerciales europeas, otorgó a ambas naciones una posición económica y

${ }^{38}$ Sobre la historicidad del conflicto Argentina-Brasil, ver Scenna, Miguel Angel: Argentina-Brasil. Cuatro siglos de rivalidad, Buenos Aires, 1974. Una sintesis del problema, con una reseña de las respectivas versiones antagónicas, está expuesta en el trabajo de Vivien Trias: Brasil-Argentina, clave de la integración latinoamericana: ¿Dependiente o liberadora?, en Nueva Sociedad, (Ca- racas), noviembre-diciembre de 1979, pp. 105-126. 


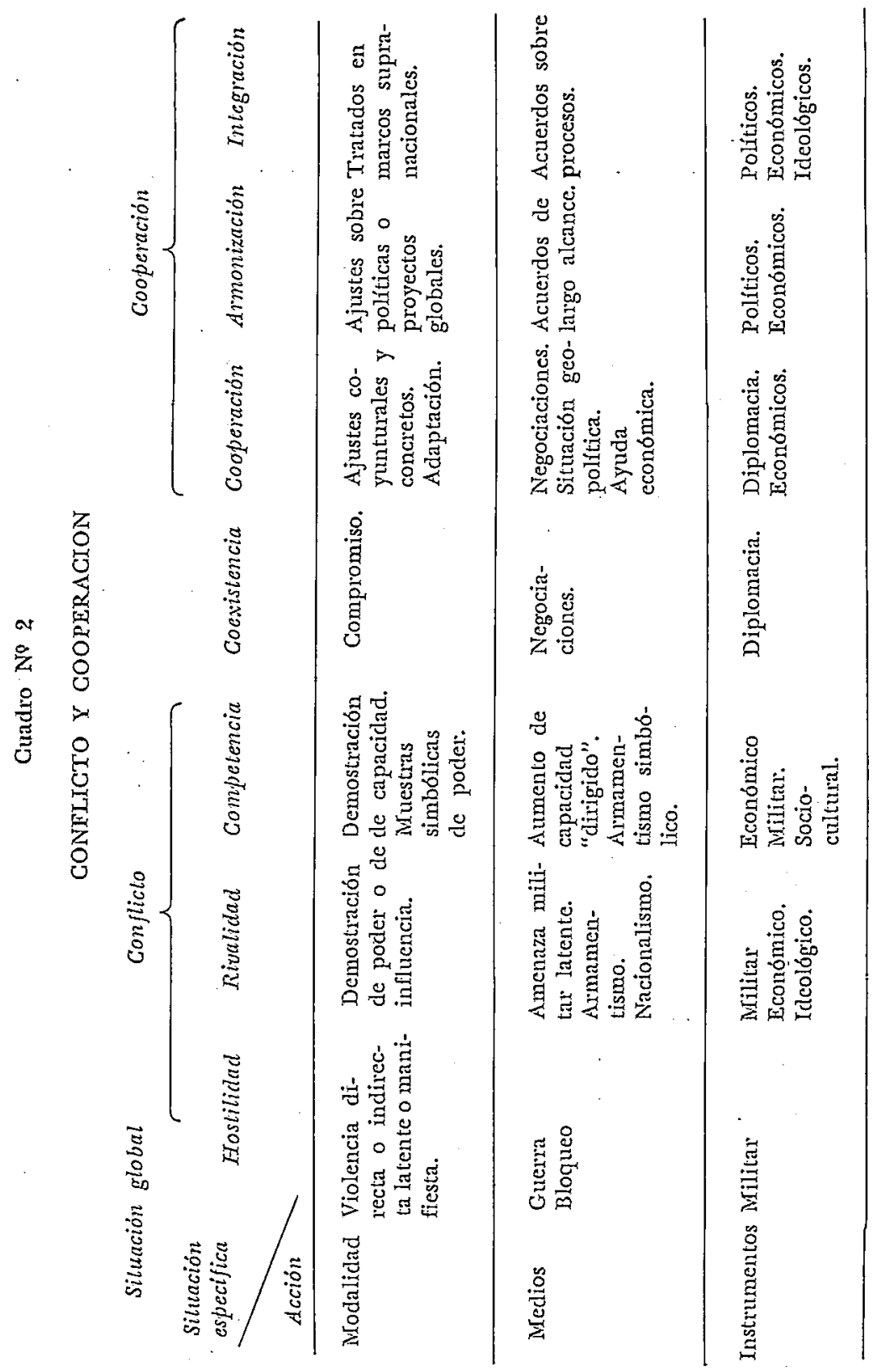

ḿilitar expectante en el marco latinoamericano a fines del siglo pasado. 
La relación comercial hacia el exterior determinó en gran parte las diferencias entre ambos países, que habrían de pesar en sus disputas en el presente siglo. Mientras Brasil, a partir de su auge exportador del café, se ligó muy temprano al ascendente poder de EE. UU., Argentina permaneció hasta muy avanzado el presente siglo -manteniéndose una fuerte tendencia hasta hoy-orientando sus relaciones hacia Europa, donde se concentraba el gran mercado para la exportación de sus productos ganaderos y agrícolas. En Ia Segunda Guerra Mundial, mientras Brasil enviaba una Fuerza Expedicionaria a la campaña de Italia, Argentina rompió relaciones con el Eje en 1944 bajo la presión de todos los países americanos. Tomando en cuenta la dominencia de EE. UU. en América Latina, especialmente después de la guerra, puede explicarse la diferencia de "status" que consiguio Brasil respecto a Argentina en todos los campos, especialmente en el económico ${ }^{39}$. Ello, sin embargo, no ha sido suficiente para invertir la supremacía argentina en el marco de la modernización, especialmente en lo referente a los indicadores de desarrollo social. El grado de desequilibrio estructural brasileño no sólo es mayor que el argentino, sino también que otros países del Gontinente. En este punto reside la relatividad del alto crecimiento económico brasileño frente al nivel casi estacionario del argentino en los últimos años ${ }^{40}$.

En el nivel regional, el conflicto entre ambos países se ha concentrado, desde la época de la Independencia, en la influencia sobre las zonas y países limítrofes y, especialmente en los últimos 20 años, 'en el aprovechamiento de los recursos de soberanía compartida en la Cuenca del Plata. En el primer sentido, el antagonismo ha determinado incluso los elementos territoriales de Uruguay y Paraguay. La superficie ocupada hoy por el primer país fue motivo de constante controversia durante la época colonial entre portugueses y españoles, y produjo la guerra entre Argentina (entonces

"Una muestra del "status" especial de Brasil por parte de EE.vu., es el convenio firmado por ambos países en febrero de 1976, mediante el cual se estatablece la celebración de consultaciones dos veces al año entre ambos paises sobre aspectos comerciales $y$ de politica mundial.

10

$\begin{array}{cccc}\text { Grado de } & \text { Alfabetismo } & \text { Esperanzas } & \text { Crecimiento } \\ \text { urbanización } & \text { (adultos) } & \text { de vida } & \text { económico del PIB } \\ \% 1975 & \% 1975 & (1975) & \text { per cápita (1970-77) }\end{array}$

\begin{tabular}{lllll}
\hline Argentina & $80 \%$ & $93 \%$ & 68 & 1,8 \\
Brasil & $60 \%$ & $64 \%$ & 61 & 6,7 \\
\hline
\end{tabular}

FUENTE: Informe Económico Mundial, 1978, Banco Mundial y 1979 World Bank Atlas. 
Provincias Unidas del Río de la Plata) y Brasil (1825-28), que terminó con la intervención directa de Inglaterra y la creación del Estado de Uruguay, como una garantía de que ninguno de los dos grandes países controlara monopólicamente la desembocadura (y el comercio) de la Guenca. La política de la nueva nación se vio, sin embargo, sometida a la intervención permanente de ambos vecinos hasta la guerra de la Triple Alianza (1865-70), en la cual argentinos y brasileños, unidos a la fracción de los "colorados" uruguayos, prácticamente arrasaron con Paraguay. Este país había sido aislado de la controversia platense y de la influencia económica europea bajo el dominio del Dr. Francia (1811-40) ${ }^{41}$, y llevado a un estado de prosperidad económica y social durante la época de Carlos Antonio López (1841-62), y de su hijo Francisco Solano (186270). La decisión de este último de participar en el conflicto interno uruguayo y también en el argentino, puso a Paraguay a merced de una fuerza superior, formada por países tradicionalmente antagónicos, "pero con intereses comunes coyunturales. Las décadas finales del siglo asistieron a la integración nacional y a la expansión económica de Argentina y a la constitución de la República brasileña, cuyos mayores éxitos en su diplomacia fueron logrados durante la época del Ministro Barón de Rio Branco, dilatada hasta los primeros años del siglo 20. Mientras Argentina incorporaba todo el "interior", incluyendo toda la Patagonia (largamente disputada con Chile), Brasil, sin apelar al conflicto bélico, anexó 835 mil $\mathrm{Km} .{ }^{2}$ a costa de todos sus vecinos, de los cuales 484 mil correspondieron a sus cuatro vecinos de la Cuenca del Plata ${ }^{42}$. En el presente siglo, la consolidación de las fronteras y de las soberanías de cada Estado, han causado una modalidad indirecta de influencia por parte de los dos grandes países de la Cuenca sobre los pequeños, expresada fundamentalmente a través de vínculos económicos. A pesar de la limitada capacidad real de cada uno de estos tres Estados -Bolivia, Paraguay y Uruguay- ellos han podido fluctuar entre ambas tendencias dominantes, obteniendo algunos beneficios, como veremos en las siguientes líneas.

4. El punto central de conflicto y cooperación. El aprovechamiento de los rios de la Cuenca

A pesar de ser una de las zonas más ricas en recursos naturales del

*1Sobre la época de Francia ver: Schmelz, Frieder: Die Isolation Paraguays im 19. Jahrhundert, Tesis de Magister (sin publicar). Institut für Politische Wissenschaft de la Universität. Heidelberg, 1979.

${ }^{42}$ Sobre las ganancias territoriales de Brasil, ver mapa en: Bailey Norman: Latin America in World Poltics, N. York, 1967, p. 57. 
Continente, ha sido el aprovechamiento de las aguas de sus grandes ríos, especialmente con fines energéticos, lo que ha movido a los países de la Cuenca a interaccionarse, tanto en relaciones conflictivas, como cooperadoras. La formación de grandes centros industriales en la Guenca misma, como São Pàlo y Buenos Aires, y la expansión industrial hacia otras zonas cercanas, exigieron a Brasil y a Argentina un creciente gasto en energía, situación que se agravó a partir de la crisis de 1973. En este terreno, sin embargo, Brasil tuvo más previsión que su vecino del sur, al iniciar estudios y obras de aprovechamiento hidroeléctrico de los ríos de la Cuenca en los tramos de su soberanía ya en la década del 50. En Argentina, a pesar de la existencia de informes orientados en esa dirección en la misma época de actividad brasileña, se desechó la vía hidráulica por la vía nuclear para satisfacer las necesidades energéticas ${ }^{43}$. Recién a fines de la década del 60, al encontrarse en estado avanzado todo el plan brasileño no sólo de aprovechamiento energético, sino el múltiple del Alto Paraná y de sus afluentes, se iniciaron las protestas argentinas $y$ un apresuramiento para iniciar proyectos destinados al mismo fin ${ }^{44}$. En 1973 fueron creadas mediantes sendos tratados las entidades binacionales Itaipú (Brasil-Paraguay) y Yacyretá-Apipe (Argentina-Paraguay), con la finalidad de administrar la construcción de dos represas situadas en los respectivos territorios compartidos, a una distancia de $460 \mathrm{Km}$. En el mismo año (en mayo), se dio a conocer un tercer proyecto destinado a construir una represa en la zona de Corpus, situada en medio del lugar elegido para los dos proyectos originados por los tratados mencionados.

La cercanía entre Itaipú y Corpus (aprox. $260 \mathrm{Km}$.), provocó un problema de carácter técnico, que, por su naturaleza, obligó a negociar a las tres partes interesadas, especialmente a Argentina y Brasil, y que devino en una controversia política, dada la rivalidad tradicional entre ambas partes. El problema consistía en que las características de ambas represas debían armonizarse para no perjudicar el mutuo rendimiento. Un determinado potencial de la represa, construida aguas arriba, puede ser perjudicial para el aprovechamiento de la situada aguas abajo. Una determinada altura de ésta, a la vez, puede perjudicar el potencial previsto para aquélla. De ahí que la controversia técnica se reducía a la cota (altura) de Corpus y al número de turbinas de Itaip ${ }^{45}$. La discusión se centró

TrYer Quaglotti de Belis, ob. cit., pp. 43-44.

wer Rojas, Isaac F.: Intereses argentinos en la Guenca del Plata. Buenos Aires, 1975, Luder, Italo A.: La Argentina y sus claves geopolíticas, Buenos Aires, 1974; Casella, Alberto/Freyre, Felipe: La energética y el desarrollo de la Cuenca del Plata, Buenos Aires, 1973.

${ }^{45}$ Quaglotti de Belis, ob. cit., pp. 48-49. 
durante largo tiempo en el ámbito jurídico-doctrinario, respecto al problema del uso de las aguas de ríos internacionales de curso sucesivo, el que se amplió al considerarse por algunas posiciones la cuenca hidrográfica como una "unidad geofísica" y, por lo tanto, como una "entidad jurídica por sobre la diversidad jurídico-política-administrativa que ofrecen los Estados"46. Habiéndose logrado un mínimo reconocimiento por parte de Brasil de que no existía un derecho de uso absoluto sobre un recurso de este tipo cuyas consecuencias podría acarrear perjuicios "sensibles" a otros países co-partícipes de él'ti, la discusión entró en el marco concreto de las represas, las cuales - por lo menos Itaipú-, ya se encontraban en fase de construcción a la altura de 1977 o -en el caso de Corpusde estudio muy avanzada.

Después de largas conversaciones centradas en las ya mencionadas conversaciones Tripartitas, pero en las cuales también tuvo lugar una vasta gama de discusiones bilaterales (entre las tres parejas de países), se llegó al Acuerdo firmado el 19 de octubre de 1979 en Ciudad Presidente Stroessner. El Acuerdo consistió esquemáticamente en:

a) El nivel de agua máximo normal de operación del embalse de la presa de Corpus se establece en la cota 105 metros sobre el nivel del mar ( $N^{\circ} 5$, letra a) del Acuerdo).

b) Itaipú podrá operar con la flexibilidad que aconseje su mejor utilización, hasta la totalidad de su potencia, la que consiste en la resultante de 18 turbinas con una potencia nominal de $700 \mathrm{MG}$ cada una, con un caudal erogado máximo del orden de $12.600 \mathrm{me}$ tros cúbicos por segundo. La flexibilidad de operación de Itaipú está limitada por determinadas variaciones del nivel clel agua consideradas aptas para la navegación. (No 5, letras b) y c) del Acuerdo) .

c) Se preserva detalladamente la mantención de las condiciones

${ }^{4}$ Sobre la controversia jurídica sobre el uso de los ríos internacionales -especialmente de curso sucesivo- respecto de la Cuenca del Plata, ver Barberis, Julio: El aprovechamiento industrial y agrícola de los ríos de la Cuenca del Plata y el Derecho Internacional, en: Derecho de la Integración, No 16, junio cle 1974, pp. 47-84. Sobre las nuevas teorías respecto a la unidad territorial de las cuencas hidrográficas y sus consecuencias para su regulación jurídica internacional, ver Chiesa Nelly Eve: El aprovechamiento compartido del recurso hidroeléctrico internacional no marítimo: Problemática estructural, técnica y jurídico-internacional, en: Integración Latinoamericana, No 41, noviembre de 1979, pp. 34-53.

Esta posición fue adoptada en la rv Conferencia de Cancilleres de la Cuenca del Plata (Asunción, junio de 1971), mediante la Resolución 25, en la que sc establece que respecto a los ríos internacionales sucesivos de soberanía compartida, "cada Estado puede aprovechar las aguas en razón de sus necesidades, siempre que no cause perjuicio sensible a otro Estado de la Cuenca". (Punto 2 de la Resolución). 
de navegabilidad del río Paraná, así como el medio ambiente, la fauna, la flora y la calidad de las aguas del río.

d) Se estipula la cooperación entre las partes respecto a aspectos operativos en las respectivas obras.

e) Se deja constancia de la necesidad de prevenir el ocasionamiento de perjuicios sensibles, señalándose que su "apreciación $y$ calificación" no podrán definirse unilateralmente ni por los Estados afectados ni por aquel o aquellos que presumiblemente los hayan ocasionado ( $N^{\circ} 5$, letra g) del Acuerdo) 4 .

\section{La fase cooperativa argentino-brasileña. Mayo-agosto de 1980}

Las visitas del Presidente Figueiredo a la Argentina en mayo de 1980, y del General Videla a Brasil en agosto, han abierto lo que el mismo Presidente argentino calificó como "un nuevo y promisorio ciclo en nuestras relaciones bilaterales" 4 . A pesar de que en el pasado hubo coyunturas en las que ambos países actuaron conjuntamente, incluso en la perspectiva de promover planes conjuntos de cooperación - como la reunión de Uruguaiana entre Frondizzi y Quadros en 1961-, el conjunto de convenios firmados en 1980 no tiene parangón histórico tanto por su volumen como por sus proyecciones $^{50}$.

La apertura de una fase de cooperación entre los dos países no sólo tiene su base en la larga negociación de las Tripartitas sobre el Paraná. Más que de ello, la búsqueda de planes conjuntos arranca de las dificultades que ambos países enfrentan en el marco del sistema económico internacional y en las realidades de sus procesos político-económicos internos.

Respecto al primer punto, juega un rol decisivo el problema de la energía. Aunque para Argentina el volumen de importaciones de petróleo no alcanza la magnitud que en el caso brasileño (ver punto siguiente), para ambos paises constituye una preocupación vital el prepararse para la continuación o el agravamiento de la

${ }^{45}$ Ver texto del Acuerdo en Estrategia, 61/62, 1979/1980, pp. 90-95.

Discurso pronunciado por el Gcneral Videla en el banquete ofrecido por el Presidente Figueiredo el 19 de agosto de 1980 en Brasilia. (Pág. 2 del texto oficial).

${ }^{5}$ En las reuniones presidenciales de mayo de 1980 fueron firmados 11 convenios sobre diversas materias. En la declaración conjunta de los presidentes además, fueron anunciados planes de cooperación en otros 9 ámbitos. (VerDeutsche Bank, Wirtschaftsbericht Lateinamerika, Juni 1980, p. 8).

Como resultado de las conversaciones celebradas en Brasil en agosto de 1980, fueron firmados 7 acuerdos y convenios, algunos de los cuales destinados a complementar a los firmados en mayo. Ver Informaçaos aos Gredenciados No 265/80, Secretaria de Informaçoes, Gabinete do Ministro de Estado, Brasilia, 20. 8. 1980). 
coyuntura energética en el mercado mundial. De ahí que, junto con el aprovechamiento de sus recursos hidroeléctricos -que son cuantiosos pero no ilimitados- ambos países han dado gran relevancia al desarrollo de la energía nuclear. En este campo Argentina tiene una experiencia más antigua, con un reactor ya en funciones desde 1974 (Atucha I), lo que le significa disponer de un manejo tecnológico más avanzado que Brasil. Este, por otra parte, tiene en marcha un proyecto de construcción de cuatro unidades nucleares para entrar en funciones entre 1979 y 198651. Argentina, por su parte, está desarrollando un plan de construcción de cuatro nuevas centrales nucleares (de $600 \mathrm{MW} \mathrm{c/u}$ ), aparte de la Atucha I y de la central Río Tercero, que actualmente erige un consorcio ítalo-canadiense ${ }^{52}$.

El principal convenio firmado entre ambos países en mayo, que fue ampliado en agosto, correspondió a la cooperación en el campo nuclear. El convenio contempla el desarrollo común de unidades nucleares (experimentales y "power" reactores), de producción de elementos radiactivos, de explotación de uranio, de colaboración en materia tecnológica, de especialización de personal y de mecanismos de seguridad en el proceso nuclear de generación de energía.

El segundo convenio se refiere a la cooperación en materia de energía hidroeléctrica, específicamente en lo relativo al aprovechamiento del tramo común del río Uruguay, cuyos planes ya estaban en su fase preliminar desde 1972.

En los acuerdos restantes de mayo y agosto aparecen nuevamente temas ligados a la energía, como el relativo a la interconexión de los sistemas eléctricos de ambos países y al intercambio de experiencias en el desarrollo de fuentes no convencionales de energía (Alcohol).

Según opiniones de algunos estudiosos argentinos $Y$ brasileños, la actual fase de cooperación en ningún caso representa una anomalía en las relaciones entre los dos países, sino, por el contrario, cons-

" $\mathrm{La}_{\mathrm{a}}$ construcción de los reactores brasileños fue encargada al consorcio alemán Kraftwerk Union (KWU), en virtud de un convenio sobre cooperación en el campo del uso pacifico de la energía nuclear firmado por Brasil y la RFA el 27. 6. 1975. (Sobre Ios detalles técnicos ver Atomwirtschaft, März 1976, pp. 132-133. El texto del convenio mencionado verlo en Europa Archiv, Folge $18 / 75$, p. D. 487 ).

Segúin el cronograma del plan nuclear brasileño, la puesta en funciones de las centrales entre 1979-1986 significaría que el uranio pasaría a significar el 4,6 del consumo total de energía del pais al final del periodo $(1978=0)$ con un total de 7.761.000 tep. (Ver Ministerio das Minas e Energia: Balanço Energetico Nacional, 1978, p. 14). Por otra parte, la creciente producción de uranio y las proyecciones existentes respecto a las reservas, permitixán a Brasil autoabastecerse en materia prima para su plan nuclear en 1984. (Ver Ministerio das Minas e Energia: Ob. cit., p. 77) .

aVer Deutsche Bank: Wirtschaftsbericht Lateinamerika, März 1979, p. 10. 
tituye el inicio de una etapa "real" de ellas, cerrando una fase "aparente" determinada por elementos ideológicos (nacionalistas) - derivados de distorsiones o inestabilidades internas. Según estas opiniones, los nuevos desafíos del desarrollo provenientes de la situación económica mundial eliminan la relevancia que pudieran tener factores histórico-ideológicos (como el concepto de hegemonía en América Latina) en favor de elementos pragmáticos, como el hecho de que una política común de los dos países más podero. sos del Continente - por ejemplo en materia de energía y de recursos naturales- puede significar para ambos una mejor posición negociadora en el ámbito mundial.

Como factores internos influyentes en esta fase de cooperación argentino-brasileña, dos tienen un rol importante. EI primero se refiere al estancamiento del modelo económico brasileño, especialmente manifestado en su creciente y enorme endeudamiento externo (entre 1973 y 1979 aumentó de 13,8 millones a 49,5 mil millones de dólares) ${ }^{53}$, y en las dificultades para llevar a cabo proyectos de desarrollo de gran envergadura (como es el caso del mismo programa nuclear que ya no pudo ser cumplido en su primer cronograma). Con ello, la imagen de "gran poder" que Brasil había proyectado en América Latina, especialmente entre sus vecinos, y que había sido estimulada por los geopolíticos de la ESG, se ha circunscrito a la tealidad de un país, cuyos problemas de país subdesarrollado se hacen aún más difíciles de superar debido a sus dimensiones.

El segundo factor - ligado en cierta medida a lo anterior- es la recuperación de una cierta coherencia en la política exterior argentina respecto a la Guenca del Plata, y especialmente frente a Brasil.

E3

BRASIL: ENDEUDAMIENTO EXTERNO Y RESERVAS EN DIVISAS

(En miles de millones de dólares)

$\begin{array}{lllllll}1973 & 1974 & 1975 & 1976 & 1977 & 1978 & 1979\end{array}$

\begin{tabular}{lrrrrrrr}
$\begin{array}{l}\text { Endeudamiento } \\
\text { externo bruto }\end{array}$ & 12,6 & 17,2 & 21,2 & 26,0 & 32,0 & 43,5 & 49,5 \\
$\begin{array}{l}\text { Reservas en divisas } \\
\begin{array}{l}\text { Endeudamiento } \\
\text { externo neto }\end{array}\end{array}$ & 6,4 & 5,2 & 4,0 & 6,5 & 7,2 & 11,8 & 9,5 \\
\hline
\end{tabular}

FuENTE: Deutsche Bank: Wirtschaftsbericht Lateinamerika, febrero 1980, p. 15. 
Debido al crecimiento brasileño entre 1968 y 1973, y al estancamiento argentino agudizado en esos mismos años, la visión creciente en Argentina respecto a las relaciones con Brasil fueron cada vez más determinadas por la lógica geopolítica, consistente en entender a Brasil como país expansionista en fase de crecimiento, y tradicio. nalmente rival de la Argentina. A esta visión se vino a sumar la crisis política interna argentina, cuyo centro estuvo en el gobierno peronista 1973-1976, el que afectó a todo intento de continuidad de la política exterior frente a Brasil, La reducción de las bases para la interpretación expansionista de la política brasileña y la estabilidad lograda por el régimen autoritario argentino a fines de la década, han contribuido a que la posición argentina frente a su gran vecino del norte se haya vuelto más pragmática y cooperativa $y$, al mismo tiempo, a utilizar una diplomacia adecuada a tal política. Desde ese punto de vista es posible entender lo activo que fue el rol argentino en la apertura de esta fase de cooperacion con Brasil.

5. Las consecuencias internas del proceso para cada pais de la Cuenca

El uso hidroeléctrico del Paraná traerá importantes consecuencias para el desarrollo de los tres países involucrados. Para Brasil, representa un significativo avance en poder sustituir en parte el alto consumo de petróleo que representa el $40 \%$ del total de sus importaciones (328,9 millones de barriles en 1978). El aprovechamiento para la generación de energía eléctrica que otorgará Itaipú, significa un enorme aumento de capacidad, considerando que Brasil -a diferencia de casi todo el resto de América Latina- ha radicado en la Hidráulica más del $90 \%$ de su producción de energła eléctrica ${ }^{0} 4$.

Itaipú, con una potencia instalada de $12.600 \mathrm{MW}$ (la represa más grande del mundo), representará el $45 \%$ de la capacidad instalada en operación en Brasil en 1979. De su producción (75.000

BRASIL. PRODUCCIÓN DE ENERGÍA ILLÉCTRICA

GWh

\begin{tabular}{rrrrr} 
& Hidro & & Nuclear & Total \\
\cline { 2 - 5 } 1967 & 29.189 & 5.049 &.-- & 34.238 \\
1977 & 92.943 & 6.926 &.-- & 99.869 \\
1987 & 225.917 & 10.521 & 26.761 & 263.199 \\
\hline
\end{tabular}

Fuente: República Federativa do Brasil. Ministerio das Minas e Energia: Balanço Energético Nacional 1978, p. 96. 
millones de KWh/año), Brasil asegura la mitad y (según el texto del Tratado de Itaipú), tiene preferencia para comprar el excedente paraguayo, el que dadas las necesidades de este país se estima muy alto.

Para Paraguay, los proyectos hidroeléctricos, especialmente Itaipú, traerán efectos muy significativos para la estructura interna económica y social, especialmente en lo referente al aumento ostensible del ingreso nacional y a la modernización en algunos sectores de la empresa y de la burocracia estatal. Tomando en cuenta que las necesidades del país en energía son cubiertas por una mínima parte de la producción que tendrá Itaipú, Paraguay se encuentra ante el dilema que un diario de Asunción resumió como "exportar o consumir"ø5. La firma del Tratado de Itaipú estuvo influida poderosamente por la idea de que Paraguay debería ceder a Brasil la casi totalidad de la producción que le correspondía -es decir la mitad del total- lo que proporcionaría a Paraguay un ingreso calculado de 600 millones de dólares en 1989 (a precios de 1979), equivalente a $1 / 4$ del PNB del año $1978^{50}$. Estos probables resultados, sin embargo, parecen diluirse un tanto, debido a que en el caso de cesión de parte de la energía, Paraguay debería concurrir en un volumen mayor al costo general de la obra, lo que ha provocado algunas opiniones en el sentido de planificar el crecimiento indus. trial, de tal modo que pueda haber un alto consumo interno de energía, exportando a Brasil sólo una parte ${ }^{57}$.

Por otra parte, Paraguay dispondrá a partir de 1989, de parte de la producción de la represa Yacyretá, compartida con Argentina. Este proyecto, aunque de grandes dimensiones, tendrá una potencia mucho menor que la de Itaipú (2.700 MW en Yecyretá, y 12.600 INW en Itaipú), en la cual, sin embargo, se prevé una mayor participación de la empresa paraguaya a partir de la experiencia ganada en Itaipú. El proyecto Corpus, se encuentra aún en fase de estudio, pero tendrá mayores dimensiones que Yacyretá.

Para Argentina, la construcción de complejos hidroeléctricos tiene un significado más político (geopolítico) que económico. El problema energético de Argentina no produce gastos tan elevados en importación de petróleo, alcanzando la diferencia entre el consumo y la producción sólo a un $6 \%$ de aquél.

\footnotetext{
WDiario "Comercio" de Asunción, 21. 10. 1979 (Suplemento La Tribuna Económica), p. 2.

${ }^{-D a t o s}$ tomados de Van Dam, André: La importancia de Itaipú. La represa más grande del mundo, en: Comercio Exterior, Vol. 29, No 9, septiembre de 1979 , pp. 984-985.

Sobre un análisis del Tratado de Itaipú, ver la Tesis de Magister de Bareiro Olinda: Paraguay. Land im La Plata-Becken, (sin publicar), Institut für Politische Wissenschaft, Universität Heidelberg, junio de 1979, pp. 129-132.

ETVer Diario Comercio, ed. cit.
} 
Tabla No 2

ARGENTINA Y BRASIL. NIVELES DE CONSUMO, PRODUCCION E IMPORTAGIONES DE PETROLEO EN 1978. (EN MILLONES DE TONELADAS DE PETROLEO)

Consumo Producción Importaciones

$\begin{array}{lrrr}\text { Argentina } & 24.790 & 23.261 & 2.010 \\ \text { Brasil } & 55.054 & 8.361 & 47.755\end{array}$

Fuente: Da Silva, Leonardo: La demanda de petróleo en América Latina para 1985, en Revista de la Integración, No 41, noviembre de 1979, p. 26 (19-33) .

Por otra parte, el primer proyecto hidroeléctrico de la Guenca del Plata en funciones (Salto Grande en el río Uruguay), es un proyecto binacional entre Argentina y Uruguay, llevado a cabo sin grandes dificultades. Las represas con participación argentina en el río Paraná tiene para los militares argentinos (que han gobernado el país 11 de los últimos 15 años) una importancia geopolítica en la medida en que moderan la creciente influencia brasileña en la Guenca. El presidente de la Comisión de la Guenca del Plata de Argentina, sostenia a principios de 1978 que "el Paraná Medio hará posible la implementación de una estrategia nacional independiente y se convertirá en la respuesta geopolitica correcta (subrayado mío) a un condicionamiento en el Alto Paraná"vs. La zona argentina de la Cuenca del Plata es muy sensible a posibles obstáculos a su desarrollo, pues en ella están situados dos tercios de la estructura económica del país, industrial y agrícola, además de la gran concentración demográfica. El relativo menor interés de Argentina en la producción energética de los ríos de la Cuenca, contrariamente a Brasil, le permite negociar con sus vecinos Paraguay y Uruguay en un marco de mayores concesiones, lo que favorece las buenas relaciones políticas con ellos y mejores perspectivas de influir en el sistema de la Guenca. Es importante observar que durante la fase más compleja de las negociaciones de las Tripartitas (enero de 1979), el enviado especial argentino a Brasil insinuó tomar en cuenta los intereses de los dos restantes países de la

${ }^{68}$ Opiniones del General de Nevares al diario "La Opinión" de Buenos Aires (12. 3. 78), citadas en: Gastagninı, Daniel: Dinámica geográlica y proyectos geopolfticos en la Cuenca del Plata, en: Geopolítica (Montevideo), No 7, abril de 1979 , p. 40 (33-42). 
Guenca (Bolivia y Uruguay') en el problema del Paraná, como un modo cle mejorar su posición negociadora ${ }^{59}$.

Para Uruguay el proceso de la Cuenca del Plata representa beneficios en dos aspectos. Por una parte, significa aprovechar las consecuencias que pudiera traer un desarrollo más clinámico de toda la zona, debido a su posición geográfica que domina la salida de la Guenca en la desembocadura del Río de la Plata. Concretamente, un mayor nivel de actividad integrada en el interior de la zona permitiría a Uruguay construir un puerto con "función plurinacional" situado en la región costera atlántica, inmediatamente clespués de la línea de la desembocadura del gran río. El argumento para tal proyecto es la baja profundidad del río-que aumentará en la medicla en que su cauce lleve más residuos, como producto de las obras realizadas en el interior de la Cuenca- que obliga al uso del puerto artificial de Buenos Aires y a grandes costos de mantenimiento para sostener en funciones a Montevideoco. Por otra parte, el desarrollo de la Guenca puede significar una ventaja para la regionalización de Uruguay, atrayendo concentración demográfica y potencial industrial y de servicios al "interior", especialmente en la zona noroeste, donde está situada la parte uruguaya del interior de la Cuenca del Plata en las márgenes del alto Uruguay y del río Tucuarembó. De hecho, tal fenómeno ha empezado a tener lugar con el funcionamiento de la represa de Salto Grande 61 .

Mirado negativamente, el estancamiento del proceso de la Cuenca del Plata que hemos descrito conduce, en gran medida, al estancamiento del desarrollo uruguayo, cuya monoorientación económica agroexportaclora requiere de esfuerzos complementarios en el marco del comercio zonal y de la prestación de servicios internacionales en el marco de la zona. Por otra parte, un curso desequilibrado o desarmonizado del proceso en la Cuenca (falta de acuerdo global sobre el uso de los ríos, por ejemplo), puede significar para Uruguay llegar a ser la ríctima del proceso, especialmente desde el punto de vista ecológico-económico.

${ }^{50}$ Quaglotti de Belis, ob. cit, p. 51.

${ }^{\circ 0}$ Sobre los problemas de cegamicnto del Rio de la Plata y de la conveniencia del puerto de "aguas profundas" en la zona costexa uruguaya de Rocha, ver dos trabajos de Abadie-Aicardi, Raúl Federico: La Cuenca Platense. Acondicionamiento y Geopolítica, en: Víspera, No 7, 1973, p. 27 (23-46) y Antecedentes históricos y marco geopolítico de la Cuenca, en: Centro Latinoamericano de Economía Humana: Cuenca del Plata, Montevideo, 1977, p. 4l (31-42).

"Ver Quaglotti de Belis, Bernardo: Geopolítica, Desarrollo y Poder Nacional ( $\mathrm{I}$, en: Geopolỉtica (Montevideo), No 6, diciembre de 1978, pp. 5-15 y Errandonea, Alfiedo: Las condiciones sociales para la integración subregional. El caso de la Cuenca del Plata (II) : El área de fronteras entre Argentina y Uruguay, en: Revista Argentina de Relaciones Internacionales, No 11 , mayoagosto de I978, pp. 5-30. 
De todos los países de la Cuenca, Bolivia es quizás el caso más especial. El hecho de que tradicionalmente sus ligazones se hubiesen dado hacia el Pacifico, su lazo con la Guenca clel Plata está fijado por dos aspectos. El primero es que la Cuenca del Plata representa una alternativa de solución al problema de su mediterraneidad, el que ha sido radicado hasta ahora como un conflicto permanente con Chile. Este punto ha sido objeto de las primeras iniciativas concretas del sistema institucional del Tratado de la Cuenca, ya que el Directorio del Fondo Financiero del sistema ha considerado de interés prioritario la construcción de un puerto en la ribera boliviana del río Paraguay, que le permitirá a Bolivia no sólo un acceso al Atlántico a través de los ríos de la zona, sino la intensificacion de su comercio con sus vecinos, especialmente con Argentina, Paraguay y Uruguay. Este proyecto, denominado Puerto Busch, ha contado con un financiamiento del BID para su estudio de prefactibilidad ${ }^{2}$. Por otra parte, con la cooperación de la oxA y de otros organismos internacionales, están en marcha estudios acerca del aprovechamiento de las cuencas de los ríos Pilcomayo y Bermejo, ambos afluentes del Paraná, pero de clifícil aprovechamiento natural para la navegación, que podrían contribuir a la ligazón de Bolivia con el sistema de la Cuenca63.

El segundo elemento de ligazón entre Bolivia y la Guenca del Plata es la existencia de ricos yacimientos minerales en la zona boliviana de la Cuenca, especialmente en la zona del Mutún, donde se calcula que se encuentran una de las más grandes reservas de hierro del mundo, aparte de manganeso y probablemente gas natural. La explotación de estas riquezas han puesto un nuevo punto de conflicto entre Argentina y Brasil, entre cuyos intereses ha oscilado la conducta boliviana tradicionalmente. En este caso, sin embargo, la naturaleza de los estímulos de ambos países para participar del problema son inversos al de las represas en el Paraná. Es Argentina quien está interesada en el producto -en este caso especialmente el hierro- que cubriría en gran parte la demanda de su industria acerera e incluso posibilitaría planes exportadores. El interés geopolítico más puro corresponde a Brasil -aunque también Argentina se interesa por evitar la expansión económica brasileña en la región- para quien no es tan vital la explotación de nuevos yacimientos de hierro, dada su producción nacional en otras zonas del país. El interés de llegar a un acuerdo con Bolivia para participar en la explotación del Mutún, significa para Brasil la oportunidad de exportar hierro y justamente a Argentina, lo que resultaría relativamente barato tanto para el lado exportador co-

orVer Kempff, Rolando: Ob. cit. (1978), pp. 33 y 36.

${ }^{\circledR}$ Ver OEA (Departamento de Desarrollo Regional): Programa de la Cuenca del Plata, Washington, 1974; , e Informe de progreso del crc, noriembre de 1979. 
mo comprador, dadas las condiciones geográficas y de transporte. Por otra parte, la participación brasileña en el Mutún traería consigo un gran avance de su influencia en Bolivia -especialmente en una perspectiva comparativa con Argentina- que a la altura de 1980 ya es considerable, incluso en el ámbito financiero respecto a operaciones que afectan dixectamente la explotación del Mutún ${ }^{64}$.

Por último, es importante señalar que la ligazón de Bolivia a la Cuenca, le ha permitido convertir en cooperadoras sus relaciones con los países vecinos en la región, con los cuales en el pasado estuvieron marcadas por el conflicto o por un permanente pie de desigualdad. Después de la Guerra del Chaco (1928-35), Bolivia y Paraguay tenían el más bajo nivel de relaciones comerciales entre países vecinos de Latinoamérica, el que ha mejorado a partir del proceso en la Guenca. Respecto a Brasil y a Argentina, la posición negociadora boliviana ha mejorado a causa de la permanente rivalidad de los dos países mayores por ejercer influencia en la zona ${ }^{65}$.

\section{CONGIUSIONES}

Tomando un concepto amplio e integrador de conflicto y cooperación como el sugerido en el Guadro No 2, es posible ordenar el material histórico y empírico resultante del proceso en la Cuenca del Plata, especialmente a partir de la firma del Tratado de Brasilia en 1969. Tal ordenamiento debiera basarse en dos criterios principales: multisituacional y multigradual. Con el primero es posible ubicar a los actores en diversas interacciones entre sí, muchas veces "entrecruzadas" $y$, con el segundo, es posible subclasificar entre las distintas categorías que reviste la dualidad conflictocooperación, según el cuadro expuesto.

\footnotetext{
- Según un anuncio de la Empresa Siderúrgica Nacional boliviana (SIDERSA) de octubre de 1980, Bolivia comercializará productos derivados del hierro procedente del Mrutún con los demás países de la Cuenca del Plata. EI mismo anuncio señala que en un futuro próximo se instalará en la zona una gran planta reductora de hierro, destinada a cubrir necesidades internas, y especialmente para la exportación a Brasil. Actualmente tiene lugar un estudio de cuantificación del gas de la zona en conjunto con Brasill, Io que implica la posible construcción de un gasoducto entre Santa Cruz y São Paulo. (Cable de la EFE, publicado en ABC de Asunción, 17 de octubre de 1980, p. 3).

Sobre los intereses argentinos y brasileños en el Mutún, ver: Morais, Carlos: Das La Plata-Becken und das Projekt EI Mutún, Documento de trabajo deI grupo de investigación Cooperación y Conflicto en Ia Cuenca del Plata, Instituto de Ciencia Politica de Ia Universidad de Heidelberg, (mimeo), 1978, pp. 14-17.

${ }^{{ }^{\infty}}$ Sobre el comercio entre Bolivia, Paraguay y Uruguay, ver: INTAL-BID: Estrategias para incrementar el comercio entre Tos países de URUPABOL, Buenos Aires, 1974.
} 
Estos criterios deben servir de base para futuros trabajos66, en los cuales se profundicen las formulaciones expuestas en este trabajo. Sin embargo, con la descripción histórico-empírica de la última parte del artículo, es posible usar nuestro modelo para presentar una primera ordenación de situaciones seleccionadas. Tal ordenamiento-ejemplo se encuentra en el cuadro No 3.

${ }^{68} \mathrm{De}$ hecho, el desarrollo del modelo de cooperación-conflicto descrito en este artículo sirve de base para el estudio de otra fase de nuestra investigación sobre la problemática global de la Cuenca del Plata, destinada al análisis de la región como sistema regional de relaciones internacionales. 
Cuadro No 3

CONFLICTO Y GOOPERAGION EN LA GUENCA DEL PLATA Hostilidad Rivalidad Competencia

Guerra ArgentinaBrasil 1825-1828. Guerra de la Triple Alianza. Argentina, Brasil y Uruguay contra Paraguay, 18651870.

Guerra del Chaco. Bolivia con $\mathrm{Pa}$ raguay, 1928-I935.
Argentina vs. Brasil. Liderazgo político-económico en Sudamérica. Argentina-Brasil. Posiciones divergentes en las relaciones militares hemisféricas (decisión sobre la Fuerza Interamericana de $\mathrm{Paz}$. Argentina-Brasil. Carrera armamentista. Argentina-Brasil. Populismos nacionalistas (VargasPerón).
Argentina-Brasil. Influencia en los países limitrofes.

Argentina-Brasil. Armamentismo simbólico. (Portaaviones) .

Argentina-Brasil. Fases de

la negociación sobre el el aprovechamiento del Alto Paraná. Argentina-Brasil. Política nuclear (1968-1980). Argentina-Brasil. Aprovechamiento mineral del Mutún.

\begin{tabular}{|c|c|c|c|}
\hline Coexistencia & Cooperación & Armonización & Integración \\
\hline $\begin{array}{l}\text { Bolivia-Paraguay. } \\
\text { Participación en } \\
\text { organismos regio- } \\
\text { nales comunes, sin } \\
\text { relaciones mutuas } \\
\text { efectivas. (1935- } \\
\text { 1967). } \\
\text { Argentina-Brasil. } \\
\text { Participación en } \\
\text { OEA, TRIAR, ALALG } \\
\text { (ALADI). }\end{array}$ & $\begin{array}{l}\text { Tratado de Bra- } \\
\text { silia (1969). } \\
\text { Argentina-Brasil. } \\
\text { Posición común } \\
\text { sobre la no supra- } \\
\text { nacionalidad del } \\
\text { Trataclo de Bra- } \\
\text { silia. } \\
\text { Bolivia-Paraguay- } \\
\text { Uruguay. Acuerdo } \\
\text { sobre unupABoL. } \\
\text { Argentina-Brasil- } \\
\text { Paraguay. Acuerdo } \\
\text { sobrc armonización } \\
\text { de Itaipú y Coxpus. } \\
\text { (Octubre de 1979). } \\
\text { Argentina-Uru- } \\
\text { guay. Acuerdo sobre } \\
\text { la represa de Sal- } \\
\text { to-Grande. } \\
\text { Argentina-Brasil. } \\
\text { Mrúltiples acucrdos } \\
\text { en mayo-agosto de } \\
\text { I980. } \\
\text { Argentina-Brasil. } \\
\text { Acuerdo sobre } \\
\text { aprovechamiento } \\
\text { del rio Uruguay. }\end{array}$ & $\begin{array}{l}\text { Relaciones de un } \\
\text { pafs de la Guenca } \\
\text { con otros paises: } \\
\text { Bolivia con el Pac- } \\
\text { to Andino. } \\
\text { Brasil con se.uU. } \\
\text { Consultaciones } \\
\text { binanuales sobre } \\
\text { política mundial. } \\
\text { Argentina- } \\
\text { Uruguay. Tratado } \\
\text { de límites del Río } \\
\text { de la Plata. } \\
\text { Argentina-Brasil. } \\
\text { Acuerdo sobre po- } \\
\text { lítica nuclear de } \\
\text { mayo I9so. Acuer- } \\
\text { do sobre suministro } \\
\text { de recursos natura- } \\
\text { les e intercambio } \\
\text { cientifico, técnico y } \\
\text { tecnológico de ma- } \\
\text { yo-agosto de 1980. }\end{array}$ & \\
\hline
\end{tabular}

